http://dx.doi.org/10.18675/1981-8106.vol25.n48.p200-206

\title{
INTRODUÇÃO AO ESTUDO DAS SITUAÇÕES DIDÁTICAS: Conteúdos e métodos de ensino
}

BROUSSEAU, Guy. Introdução ao Estudo das Situações Didáticas: Conteúdos e métodos de ensino. São Paulo: Ática, 2008. 128p.

\author{
Amal Rahif Suleiman' \\ ' Mestre em Educação Escolar pela Universidade Estadual Paulista (UNESP) - Campus de \\ Araraquara, São Paulo - Brasil. E-mail: amal.rahif@terra.com.br
}

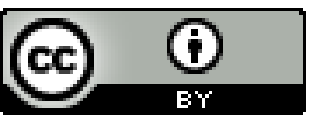

Educação: teoria e prática, Rio Claro, SP, Brasil - eISSN: 1981-8106

Está licenciada sob Licença Creative Common

Em Introdução ao Estudo das Situações Didáticas, Guy Brousseau reafirma a importância da didática da matemática como disciplina científica, no sentido de contribuir para o aperfeiçoamento da formação tanto de alunos quanto de professores de matemática.

As atividades de pesquisa do notável professor de matemática, de origem francesa, nascido no Marrocos, em 1933, tiveram início na década de 1970, quando fundou o Corem (Centro de Observação e Pesquisa no Ensino da Matemática) junto à Universidade de Bourdeaux, na França, em 1972, sendo divulgadas na América Latina na década de 1980, e começaram a chegar ao Brasil nos anos 1990. O fruto de 40 anos de trabalho sério e responsável, ancorado em experiências empíricas metódicas sobre o contrato didático na situação de ensino e aprendizagem de matemática, rendeu-lhe a condecoração da primeira Medalha Félix Klein, em 2003.

O livro que resenhamos é o texto fundamental para compreensão da teoria das situações didáticas, simbolizando a tradução de um curso ministrado pelo autor, em 1997, quando recebeu da Universidade de Montreal, no Canadá, o título de doutor honoris causa. Divide-se em três partes, que sucedem a uma Apresentação à Edição Brasileira (Benedito Antonio da Silva), e ao Prólogo à Edição Argentina (Dilma Fregona). Foi editado originalmente em espanhol, na Argentina, em 2007 e traduzido no Brasil, por Camila Bogéa, com publicação em 2008. Ainda que decorridos seis anos de sua publicação, apresentar essa obra justifica-se por retratar importante subsídio à educação matemática brasileira, uma vez que, a partir dela, ocorre o início da divulgação da teoria das situações didáticas como ferramenta de soluções a problemas que foram a origem de sua criação.

Dessa maneira, a obra é composta de uma Introdução, das três partes (A, B e C) e de uma Conclusão, sendo que cada uma das partes contém muitas subseções. Todo o texto está 
repleto de conceitos e definições utilizadas por Brousseau para compor a teoria das situações didáticas.

Introdução: Algumas questões são levantadas pelo autor, com o objetivo de apontar a relevância da matemática como conhecimento necessário para a sociedade e para os cidadãos e, ainda, perquirir qual a melhor forma de difundir esse conhecimento a fim de preparar técnicos e cientistas para que possam enfrentar os desafios do futuro, onde a matemática virá a ter papel preponderante. Nesse sentido, o sucesso da transmissão dos conhecimentos matemáticos sugere uma dependência das ciências da educação, da psicologia e da didática da matemática.

Afirma Brousseau que, hoje, a Teoria das Situações Didáticas apresenta-se como um instrumento científico que tende a unificar e integrar as contribuições de outras disciplinas, apoiar e regular o ensino de matemática. Para ele a relação didática é uma comunicação de informações, e é o professor o responsável pela organização das mensagens dessa comunicação, visando à aculturação do aluno pela sociedade. Define que o ensino baseia-se numa atividade que harmoniza dois processos: um de aculturação e outro de adaptação independente.

Na finalização da Introdução, o autor coloca um ponto fundamental: o meio que possibilita o ensino pode ser modelado, como sistema autônomo: um problema, um exercício, um dispositivo, enfim, um meio. E conceitua situação como sendo um modelo de interação de um sujeito com um meio específico que determina um certo conhecimento.

A teoria das situações de ensino, de Brousseau, está ancorada na busca das condições necessárias à efetivação da aprendizagem, desenvolvendo a noção de engenharia didática (então origem e causa da teoria), como a criação de situações que delimitam uma ação e um dos modelos usados.

A. A Modelagem das Situações na Didática: Nessa primeira parte da obra, Brousseau apresenta um levantamento histórico sobre a Teoria das Situações de Ensino, declarando que, na década de 1970, a situação funcionava como uma ferramenta para o professor, que utilizava meios (textos, material etc.); o contexto cercava o aluno, projetado e manipulado pelo professor. Posteriormente, as situações matemáticas levam o aluno a uma atividade sem a intervenção do professor. Para o autor, situação didática é um modelo que descreve as atividades do professor e do aluno. É todo contexto que circunda o aluno, nele incluídos: o professor, o aluno e o sistema educacional.

Para ilustrar uma situação didática de acordo com sua teoria, Guy Brousseau estabelece um dispositivo como um meio material (as peças de um jogo, um desafio, um problema, um exercício, fichas etc.) e as regras de interação com esse dispositivo, alegando que somente ocorre aprendizagem pela adaptação do sujeito que assimila o meio criado, ao longo do processo. Descreve a aplicação feita por ele do jogo Quem vai dizer 20?, constituída por três fases, para revisar a operação de divisão. Analisando o comportamento dos alunos nas três fases estabeleceu uma primeira classificação das situações didáticas: Situação de Ação; Situação de Formulação e Situação de Validação. 
Tais abordagens levaram o autor a determinar uma tipologia das situações na didática, em três grandes categorias: (1) Troca de informações não codificadas ou sem linguagem (ações e decisões); (2) Troca de informações codificadas em uma linguagem (mensagens) e (3) Troca de opiniões (sentenças que exercem o papel da teoria).

Graças a esses antecedentes experimentais e suas análises, Guy Brousseau define as situações didáticas: Situação de Ação: modelo implícito em que o aluno toma suas decisões sem ter consciência delas, como por exemplo, aprender um método de resolução de um problema; Situação de Formulação: requer repertórios linguísticos para formular uma informação ou um debate e Situação de Validação: meios para validar ou invalidar os esquemas de ação e de formulação. Por fim, o autor propõe a Institucionalização das situações que deram a determinados conhecimentos a condição de saber como produto cultural de uma instituição.

Ao introduzir o conceito de Dialética, Brousseau afirma que cada situação pode fazer com que o sujeito progrida, gerando uma sucessão de novas perguntas e respostas, e conclui que ação, formulação, cultural e institucionalização estabelecem uma ordem razoável para a construção dos saberes.

Quanto à atuação do professor, Guy Brousseau caracteriza três situações: Adidática, Didática e Fundamental. Na situação Adidática, o professor deve proceder de forma a não dar a resposta ao aluno, que aprende adaptando-se a um meio, no qual o professor provoque as adaptações desejadas (exemplo: uma seleção sensata dos problemas que propõe). Na situação Didática ocorre um contexto mais amplo em que a situação ou um problema escolhidos pelo professor envolve o aluno e o seu meio. Um pequeno número de situações fundamentais permite ao aluno armazenar fundamentos para cada novo conhecimento matemático (exemplo: o conhecimento das propriedades dos conjuntos numéricos e das operações para que o aluno possa dominar seu uso em momentos mais complexos).

$\mathrm{Na}$ aprendizagem de matemática, Guy Brousseau denota a otimização como sendo um meio para a adaptação das situações aos alunos: é inevitável a utilização de um meio (ábaco, lápis e papel etc.) para efetuar certos cálculos. Da mesma forma, quanto à adaptação dos alunos às situações vão ocorrer saltos e obstáculos, quando afirma: "As variantes de uma situação relativa a um mesmo saber matemático podem apresentar grandes diferenças de complexidade e, em conseqüência, levar a diferentes estratégias ótimas e também a diferentes maneiras de conhecer um mesmo saber." (BROUSSEAU, 2008, p.45). Para ele, adquirir uma concepção representa uma maneira organizada, mas particular, de considerar uma concepção matemática. Concepções adquiridas não desaparecem em benefício de uma melhor; provocam erros ou tornam-se obstáculos, os quais não podem ser ignorados, são um constitutivo do saber.

Assim, ao final dessa parte inicial, Guy Brousseau insere alguns resultados e primeiras conclusões. A modelagem das situações na didática em que o professor permite a construção autônoma dos conhecimentos matemáticos pode levar o aluno a conhecimentos localmente adaptados, insuficientes ou falsos em uma etapa posterior e ainda se transformar em 
obstáculos, enfatizando a intervenção didática do professor: "Essa construção autônoma não pode dar aos conhecimentos desenvolvidos o status de saber. [...] A intervenção didática do professor é a que permite identificar conhecimentos canônicos no que o aluno, ou os alunos, conceberam em situações autônomas." (BROUSSEAU, 2008, p.51).

B. A Teoria das Situações Didáticas: Neste segundo ponto sobre as situações didáticas, Brousseau inicia com o conceito de didática da matemática: "ciência das condições de transmissão e apropriação dos conhecimentos matemáticos úteis aos homens e a suas instituições.” (p.53). Ao modelar essa transmissão, o professor cria uma situação didática.

Na situação de ensino em que há somente interação professor-aluno ocorre redução da ação do professor e omissão das ações do aluno no meio adidático. Na situação didática o professor cria outro meio em que o aluno pode atuar de forma autônoma.

O meio didático pode estar estruturado de duas maneiras: meio material (mesmo que não haja objetos concretos, quando o professor prepara a sua aula, organiza um meio) e meio objetivo (é o aluno que atua num meio efetivo, de ação).

Para que um conhecimento tenha sentido devem ser observados seus componentes semânticos, sintáticos e pragmáticos, e a transformação do conhecimento em saber ocorre numa situação didática.

Nesta segunda parte, Guy Brousseau apresenta vários tipos de contratos que podem surgir nas relações entre emissores e receptores, durante a transmissão de conhecimentos. Há os Contratos sem Intenção Didática: em número de quatro: Contrato de Emissão (situação mínima: professor monologa e os alunos emitem ruídos, também os programas de rádio e televisão); Contrato de Comunicação (a mensagem chega ao receptor quando o emissor usa os repertórios próprios para isso); Contrato de Habilidade (é mais exigente, onde o emissor garante a validade do que está emitindo, como por exemplo, enunciar teoremas que compõem uma teoria matemática, um após o outro: os enunciados se tornam assertivas, isto é, verdadeiros) e Contrato de Produção do Saber (o emissor garante o ineditismo de sua mensagem, omitindo sua prova; exemplo, apresentar as raízes de certas equações, sem publicar o método que utiliza).

Ao descrever os quatro Contratos Pouco Didáticos, aqueles que mostram um saber novo, o autor define: Contrato de Informação (é o que está vigente na comunidade matemática para a divulgação de resultados, onde o emissor garante a novidade, a validade e a prova de sua mensagem); Contrato de Utilização dos Conhecimentos (amplia o anterior, agregando um campo de aplicações); Contrato de Iniciação ou de Controle (emissor fornece ao receptor um critério para determinar se compreendeu bem e não somente recebeu a mensagem) e Contrato de Instrução ou de Direção de Estudos (utiliza todos os dados dos anteriores e indica como se pode aprender um novo saber, por exemplo, a demonstração já é um cálculo ou um algoritmo e aquele que aprende pode verificar se executou ou reproduziu bem o algoritmo).

O autor expõe conclusões sobre os Contratos Pouco Didáticos, condensando os de Emissão ou de Comunicação como os encarregados da forma da mensagem; os de Habilidade, 
de Produção ou de Informação como responsáveis pelo sentido da mensagem e os de Utilização, Iniciação ou Instrução como sendo aqueles que permitem o uso da mensagem. Esses contratos levam em conta o projeto de fazer com que um interlocutor, tido como sujeito epistêmico, mas não efetivo, se aproprie de um saber.

Nessa parte intermediária da obra, Brousseau tece um estudo teórico do Contrato Didático, e estabelece símbolos para identificar os sujeitos desse contrato: E (aquele que aprende); P (professor); M (instituição com relação ao aluno) e I (instituição em relação ao Professor). Para ele, no contrato didático, professor e aluno, cada um imagina o que o outro espera dele e o que cada um pensa do que o outro pensa, e com isso, surgem possibilidades de intervenção, de devolução da parte adidática das situações e de institucionalização; nele a sujeição do aluno é momentânea.

Guy Brousseau afirma que existem paradoxos no contrato didático, pois para ele, este é incerto, uma vez que o professor não tem certeza de que todos os alunos vão resolver sem erros as situações e exercícios que apresenta, essa atividade perderia seu conteúdo didático e ele não a proporia mais. $\mathrm{O}$ ensino e a aprendizagem ocorrem por meio de processos que nunca estão em equilíbrio estável.

Analogamente, nomeia alguns efeitos do contrato didático, como o Efeito Topaze (a resposta é previamente determinada - como na peça Topaze, de Marcel Pagnol desmoronando o ato de ensinar, com perguntas cada vez mais fáceis); o Efeito Jourdain (o professor para evitar o debate do conhecimento com o aluno e, comprovar o fracasso, admite perceber o indício de um conhecimento sábio nas respostas, que na realidade são motivadas por significações banais - peça O Burguês Fidalgo de Molière). Outro efeito do contrato didático é o das Transposições Metacognitivas e Metadidáticas onde o professor tenta usar suas próprias explicações e seus heurísticos em lugar do conhecimento matemático. Mais um efeito refere-se ao uso abusivo da Analogia, pois os alunos podem obter a solução lendo as orientações didáticas e não por meio de um compromisso com o problema. E, finalmente, o último efeito apontado por Brousseau é o Envelhecimento das situações de ensino, no qual o professor encontra dificuldade para reproduzir a mesma aula, sente necessidade de mudar a exposição, os exemplos, os exercícios, a estrutura da aula. Afirma o autor: " $O$ ato de ensinar em si mesmo exige um compromisso pessoal intenso por parte do professor, compromisso esse que só se sustenta se for renovado. A reprodução exige então uma renovação que coloca em risco as futuras reproduções." (BROUSSEAU, 2008, p.86). A didática se responsabiliza por analisar o que foi reproduzido em uma situação de ensino, e avaliar o tempo didático dessa situação.

C. As Situações Didáticas: Componentes e Estratégias: A última parte do livro focaliza os componentes e as estratégias essenciais do contrato didático, que são a Devolução e a Institucionalização. A devolução é o ato pelo qual o professor faz com que o aluno aceite a responsabilidade de uma situação adidática de aprendizagem. Nesse caso, devolver as soluções depende da motivação do aluno, o que vincula às questões psicoafetivas. A institucionalização é o segundo componente do contrato didático, com responsabilidade 
centrada no professor: na situação de ação, na formulação, na validação, ele deve institucionalizar o saber.

Ao tratar das estratégias do contrato didático, Brousseau considera as Fortemente Didáticas (que trazem um saber novo) e os Contratos de Transformação dos Saberes Antigos. Nas primeiras, faz o exame de seis contratos fortemente didáticos: Contrato de Imitação ou de Reprodução Formal (o aluno reproduz uma atividade determinada, como por exemplo, dizer o enunciado de um teorema); Contrato de Ostensão (o professor mostra um objeto ou uma propriedade, o aluno aceita apenas ver, e deverá reconhecer em outras ocasiões, como por exemplo, definir um polinômio como uma soma de monômios não permite deduzir fatorações compatíveis com uma estrutura de anel - a base desse contrato é empirista e realista, convém às duas partes e é utilizado com muita frequência pelos professores); Contrato de Condicionamento (por repetição e recitação - teses associacionistas e behavioristas); Maiêutica Socrática (perguntas por parte do professor, aluno responde com os próprios recursos e reorganiza as respostas para avançar seus conhecimentos); Contratos Empiristas (o conhecimento é produzido pelo contato do aluno com o meio ao qual deve se adaptar métodos de Freinet e alguns métodos ativos - a Gestalt); Contratos Construtivistas (o professor organiza o meio e o aluno obtém as aquisições, recorre-se às fases adidáticas - ação, formulação e validação - para criar diferentes formas de conhecimento e o aluno adapta-se e acomoda-se a diferentes situações - Jean Piaget).

Nos contratos de transformação dos saberes antigos, Guy Brousseau aborda a memória didática, em que o professor realiza uma revisão de um saber antigo, pelas razões didáticas de um fracasso anterior, de uma adaptação a novos aprendizados, uma reorganização dos saberes adquiridos ou inversamente organizados canonicamente; os contratos de revisão dos saberes antigos instituídos por Perrin-Glorian (1992-1993), nos quais os fatos principais são reconstruídos em uma nova situação didática, sendo um dos instrumentos mais importantes da institucionalização e a Recuperação, que coloca o antigo saber em uma nova dialética.

Ao discutir os efeitos das reformas a longo prazo (os 40 anos de suas pesquisas), estabelece algumas críticas à individualização do ensino, ao considerar que "Os conhecimentos são um bem cultural comum, cuja prática só pode ser aprendida pelos alunos com um trabalho conjunto. A solução está no equilibrio.” (BROUSSEAU, 2008, p.115). Tece, igualmente, análises sobre o modelo comercial de ensino, seus objetivos, avaliações e consequências, em que os programas escolares retomam no nível seguinte os mesmos projetos de aprendizagem do nível anterior, devido às metáforas industriais e administrativas.

E, por fim, expõe os antagonismos entre duas diferentes escolhas, em outras reformas, como Matemática esotérica ou exotérica ou Matemática humanista; Sentido ou Forma; Rigor ou Eficácia; Texto do saber ou problemas (a heurística ou retorno da Geometria) e Aprendizagem por Condicionamento ou o Construtivismo.

Conclusão: Nesse tópico de conclusões gerais, Guy Brousseau (2008, p.117) afirma que " $E$ ' difícil propor uma conclusão para este texto”, levando em conta as questões do capítulo anterior. Considera suas reflexões um espaço aberto para o debate acerca da Teoria das 
Situações Didáticas e sua utilidade na prática de ensino para maior aproveitamento da matemática. Seleciona essas reflexões em direcionamentos para os professores, para a formação dos professores, para os pais e o público, para a própria ciência e para o conjunto da sociedade, todas elas com o objetivo de mostrar os interesses da didática da Matemática que estão inseridos nas referidas direções.

É na didática que o professor espera encontrar técnicas específicas e compatíveis com suas concepções e como criar na aula uma atividade científica, sem sacrificar o tempo. A didática permite a criação de um comprometimento profissional para que não ocorra a "[...] nítida tendência a reduzir as aulas a 'apoio paliativo' para erros individuais cometidos pelos alunos em seus exercícios." (idem, p.123). Apoiando-se na engenharia didática, o ensino deve se preocupar em oferecer ao aluno um conhecimento matemático que atenda suas necessidades e, permita que, em algum momento, possa encontrar na sociedade os matemáticos e os produtos da matemática que ele precisará.

Guy Brousseau faz um alerta à comunidade científica, indicando que didatas e professores devem ser avalizados para reorganizar os saberes que serão ensinados, enfatizando que a didática é também uma ciência, e não deve ser considerada como naturalmente evidente ou inútil, pois é na ciência, e mais precocemente na matemática, que os alunos podem aprender e administrar uma verdade científica, ao afirmar que "[...] somente a inserção da didática na cultura poderá melhorar a gestão política da difusão dos saberes e tornar mais democrático o seu uso e sua criação." (idem, p.124).

Por todas essas reflexões, o texto acima apresentado, nesta resenha, mostra-se como obra essencial na área de educação matemática, porque insere a didática como ciência sob a ótica de uma pesquisa de 40 anos do notável matemático, cuja iniciativa inovadora é um passo importante nessa direção e porque abre ao debate um compêndio sobre o contrato didático que se estabelece na sala de aula, onde "o ensino é o último refúgio de todos os fantasmas coletivos ou individuais, a última instância em que todas as ideologias podem se enfrentar com boas intenções." (BROUSSEAU, 2008, p.119).

\section{Referências}

PERRIN-GLORIAN, M. J. Aires de surfaces planes et nombres décimaux. Questions

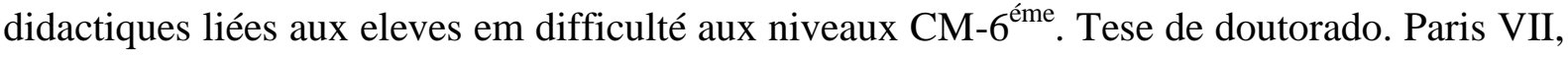
1992.

PERRIN-GLORIAN, M. J. Questions didactiques soulevées à partir d l'enseignement des mathématiques dans les classes fibles. Recherches en Didactique des Mathématiques, 13 (1/2), 1993. 